\section{NORTH STAFFORDSHIRE INFIRMARY.}

\section{CÁSE OF EXOSTOSIS OF THE TIBIA, AND OPERATION.}

By J. Sendom, M.D., F.R.C.S., \&c., lately one of the Surgeons to the North Staffordshire Infmary.

Joseph Hubball, agricultural labourer, aged 21, married, of florid complexion and healthy appearance, was admitted into the North Staffordshire Infirmary, January 5th, 1846. About two years and a half ago, his attention was first called to a "lump" in the upper and back part of the right leg, by uneasiness in the part, which was attended with occasional numbness in the ankle; there is no very marked swelling of the part, bnt the muscles of the calf, on examination, seem to be stretched, and a hard tumour can be felt firmly attached to the npper and posterior part of the tibia. A pulsating blood.rsssel can be traced on the outer edge of the tumour. The patient thinks the swelling may hare been caused by leaping. Leeches, blisters, and other measures had been resorted to before his admission. He was directed to take Potassii Iodidi, gr. iv., twice a day; and he had a strong compound jodine solution to apply to the tumour.

This plan was unremittingly pursued till the middle of April, but the tumour had become decidedly larger, and the patient was now suffering considerable pain. A consultation of my colleagues was therefore called, when I submitted for their consideration a proposal to remove the tumour by excision; this was decided upon, and the operation undertaken, May 2nd.

A free incision, commencing at the lower part of the poplitieal space, and within the inner hamstring, was extended about four inches downwards, on the inner edge of the gastrocnemius, and parellel with it. This was continued across the muscle, and carried a little upwards, so that the cut had somewhat of a hooked appearance. By this means, a flap was formed of the muscles of the calf, which was tarned upwards; two bleeding vessels were tied at this stage of the operation. The tumour now became apparent, covered only by an expansion of muscular fibres. The bouse-surgeon, Mr. S. Alford, having drawn aside the ressels and nerve, by means of a hooked copper spatula, the musculat fibres were divided so as to expose the tumour clearly; it had an extensive attachment to the tibia, and overhung its inner edge, so as to fill up the interosseal space at this part. By means of a chisel and mallet applied to its inner edge, it was partially divided; the chisel was then worked into the internal structure of the tumour, with the hand alone, and by raising the handle of the instrument, the bony mass was forced from its attachnent; a few projecting points of bone were renoved by the bone-nipper. Some lint haring been upplied to the bottom of the wound, the muscular fap was laid down, and a piece of lint placed over $i t$, and this being retuived by a bandage loosely applied, the patient was carried to his bed. Sum,$t$ Tinct. Opii, min. xxv. e Mist. Camph., oz.j. statin. Hydrarg. Chlor., gr. ir., hora somni.

The operation was effected with much less difficuliy than was anticipated. The tumonr was as large as a midille-sized potato, had a nodulated appearance, and a flesh colour, having somewhat the resemblance of large granulations; but this appearance was only superficial; internally it had a cancellated bony structure. The diameter of its base was nearly three inches.

May 3rd. The limb somewhat swelled; the bandage and outer dressings were removed, and lint soaked in warm water applied.

4th. Going on farourably; some fever; bowels have not been mored. Med. Efferr. Ol. Ricini, oz. ss. Appl. Catapl. Lini vulneri.

6th. Some erythema about the ankle. Appl. Catspl. Lini parti affectæ.

12th. Going on well; the muscle bulges from the wound, but has a healthy granulating appearance; general health good. Middle diet. White lead cerate spread on lint applied to the wound, anci support given by a baudage.

17 th. Improving. Lint wet in sulphate of zinc lotion applied to the wound, and support given with adbesive straps and bandage.

From this time the patient continued to improve. He was discharged cured, June 3ntl. Sonn after his discharge he resumed his employment as a farmer's servant. I have lately heard of him, and learn that he is perfectly well, and follows his employment without inconvenience.

The difficulties of the operation which presented themselves to myself and colleagues before it was undertaken were:-First, the danger of wounding the vessels and nerre, passing from the poplitieal space; secondly, it was thought possible that the tumour might extend so far upwards as to endunger the opening of the capsule of the joint; and lastly, if the excrescence were of a ftrm texture there might be considerable difficulty in detaching it from the bone. However, as it was considered that amputation of the limb would soon be required if the tumoar continued to increase, it was decided to undertake its removal, having first apprized the patient of the dfficulties and danger of the case. I had no apprehension that the disease was of a malignant character, as the patient had a healthy aspect, and his general health had always been good.

\section{PROVINCIAL}

\section{Alevical \& Eurgical Journal.}

WEDNESDAY, FEBRUARY 10, 1847.

We have lately had our attention drawn to an important document from Mr. Chadwick, which, although addressed to a local authority, the Town Clerk of Liverpool, and for a special purpose, yet contains the enunciation of sound principles, of general application in reference to the subject of which it treats.

This document is in the form of a letter $-a$ well-merited testimonial to the unwearied zeal, 